\title{
DYSPROSIUM COLLOIDS PREPARED IN POLAR ORGANIC SOLVENTS
}

\section{GALO CÁRDENAS TRIVIÑOI*, OLIVIA GODOY GUZMÁN ${ }^{I}$ AND GUILLERMO CONTRERAS ${ }^{2}$}

\author{
${ }^{1}$ Laboratorio de Materiales Avanzados, Departamento de Polímeros \\ ${ }^{2}$ Departamento de Química Analítica e Inorgánica \\ Facultad de Ciencias Químicas, Universidad de Concepción, Casilla 3-C, Concepción, Chile
}

(Received 3 August 2007 - Accepted 13 November 2008)

\begin{abstract}
Dysprosium colloids in organic solvents (2-methoxyethanol, 2-propanol and 1,2-dimethoxyethane) have been obtained by the CLD method al $77 \mathrm{~K}$. These colloids were characterized by zeta potentials, UV-Vis, TEM, electron diffraction and EDX measurements.

Colloid stability depends on both solvent and metal concentration. The highest stability was obtained in 2-methoxyethanol, which is in agreement with previous results for other lanthanide colloids already reported. Zeta Potential $(\xi)$ of the colloids ranges between 0.1430 and $1.945 \mathrm{mV}$.

UV-Vis spectra exhibit bands in the UV region. 2-methoxyethanol shows bands at 211 and $283 \mathrm{~nm}$, which is very similar to 1, 2-dimethoxyethane colloids (222 and $273 \mathrm{~nm}$ ). However, the 2-propanol exhibits a band at $207 \mathrm{~nm}$ for a $2.5 \mathrm{E}-4 \mathrm{M}$ concentration.

At the TEM particle size distribution, 2-methoxyethanol colloid exhibits ranges from 2.5 to $11.6 \mathrm{~nm}$, but the 2-propanol shows ranges from 2.5 to $4.3 \mathrm{~nm}$, depending on the polarity of the solvent.

The electron diffraction gives the most common phases, corresponding to Dy (002) and $\mathrm{Dy}_{2} \mathrm{O}_{3}(110)$.

EDX confirms the metal presence in the colloids. Luminescence measurements for Dy-2-methoxyethanol at $280 \mathrm{~nm}$ exhibit a higher quantum yield at $2.0 \mathrm{E}-3$ and 5.0E-4 which indicates a higher transfer from the metal ion to the solvent.
\end{abstract}

Keywords: Dysprosium colloids, nanoparticles, luminescence, zeta potential.

\section{INTRODUCTION}

There are several aspects in the magnetic and spectral behavior of the lanthanides which are different from the " $d$ " block of the transition metals. The $4 f$ electrons in the orbitals are more shielded respect to the external. For this reason, the stages originated from the several $4 f^{\mathrm{n}}$ configuration are slightly affected by the media surrounding the ions and remains invariable in particular for all third row compounds ${ }^{1}$.

The spin-orbital coupling constant is extremely large. As a consequence, but with some exceptions, the lanthanide ions possess fundamental stages with only one well defined value of the total angular moment $J$, with the following lowest $J$ value and with several energies greater than the $K T$ value. Furthermore, the highest values are non-populated.

The great number of metallic complexes absorbs visible light and/or UV, but only light emission in the UV range producing, luminescence. The trivalent lanthanide ions and their complexes are known by their luminescence properties due to the presence of sharp bands corresponding to the $f-f$ transitions of the metallic atoms and properties of the excited states of lanthanides ions have been extensively studied ${ }^{2,3}$. Transitions between f orbitals of $\mathrm{Ln}^{3+}$ are strictly forbidden in pairs. However, several $\mathrm{f}-\mathrm{f}$ transitions possess forbidden spin even if the spin-orbital coupling increases the forbidden. A good example in which luminescence of the lanthanide complexes is analyzed was described by Liu ${ }^{4}$. Later on, different studies on luminescence of several europium compounds have been reported ${ }^{5}$. Besides, luminescence properties of lanthanid ions in solution and their chelates ${ }^{6}$ are an important issue to be considered for future applications ${ }^{7-10}$

Due to their interesting luminescence properties of lanthanide elements and their compounds, the attention has been focused on the colloidal synthesis in organic solvents.

A similar method to our CLD method intended in obtaining lanthanide colloids was reported by Mirkovich et al. ${ }^{11}$. This method is based on the reduction of lanthanide-dithiocarbamate complexes in order to generate spherical nanoparticles of the size ranging from 5 to $8 \mathrm{~nm}$.

By the CLD method it is possible to obtain a series of Dy colloids in oxygenated organic solvents such as 2-methoxyethanol, 2-propanol and 1, 2-dimethoxyethane. The election of these solvents is due to their ether and alcohol functional groups, as well as their higher polarity.

Colloid stability changes, depends on the participating solvents. Stabilization is related to charge transference processes and inductive effect of electron donors that are able to produce free electrons from the oxygen atoms present in the molecule solvents, stabilizing the dysprosium clusters.

Several years ago it was observed that particle surface properties play an important role in the colloid stability ${ }^{12,13}$. The fundamental principle behind it is the increase on the particle surface. The higher increase in the surface area is due to the presence of higher number of nanoparticles on the surface. Colloidal particles are nanoparticles that can slowly get agglomerated at room temperature, especially in non-aqueous solvents ${ }^{14}$. However, the atoms of the surface attract atoms either from other particles or from the solvent ${ }^{15}$.

\section{EXPERIMENTAL}

\section{Metal atom reactor}

Metal atom reactor has been already described ${ }^{16,17}$ as a typical example, an alumina-tungsten crucible that was charged with $0.152 \mathrm{~g}$. of Dy metal (lumps). Dried 2-methoxyethanol was placed in a ligand inlet tube and freeze-pumpthaw degassed with several cycles. The reactor was pumped down to 0.008 mbar while the crucible was warmed to red heat. Liquid nitrogen filled a Dewar and it was placed around the vessel and $\mathrm{Fe}$ and 2-methoxyethanol $(70 \mathrm{~mL})$ were deposited over $1 \mathrm{~h}$ using 30 to $40 \mathrm{~A}$. The matrix was a blue/purple color at the end of the deposition. The matrix was allowed to warm slowly under vacuum, by the removal of the liquid nitrogen Dewar for $1 \mathrm{~h}$, upon meltdown a brown colloid was obtained. After addition of nitrogen up to $1 \mathrm{~atm}$., the colloid was allowed to warm for another $0.5 \mathrm{~h}$ at room temperature. Then, the solution was siphoned out under nitrogen into a flask ware. Based on metal evaporated and acetone inlet, the molarity in metal could be calculated. Several concentrations were prepared under the same conditions. No presence of hydrogen evolved during the metal evaporation was observed. The vacuum remained constant during the evaporation

\section{Transmission electron microscopy (TEM)}

The electronic micrographs were obtained through the Jeol JEM EX- 1200 II equipment whit $4 \AA$ of resolution. A drop of the colloid dispersion of Dy/ solvent was deposited on a $\mathrm{Cu}$ grid of 150 mesh covered with a thin carbon film.

The particle size was determined by optical measurements and the diameters of a specific particle population were measured randomly. Data set was represented in frequency histograms, to which distributions of both Gaussians and normal types were adjusted in order to obtain the respective measurements.

\section{UV-Vis absorption}

The absorption spectra of the colloids, from 200 until $500 \mathrm{~nm}$, were 
measured at $25^{\circ} \mathrm{C}$ in a Spectronic Genesis 2 model spectrophotometer, using a quartz cell. The background was set up with the proper solvent and then, each colloid sample was examined.

\section{Electrophoresis}

The electrophoresis experiments were carried out by means of a Zeta meter system 3.0+ in which, a quartz cell was used and then, rinsed with ionized water and, once this processes had been done, rinsed again with the corresponding solvent. The cell was filled up with the colloid avoiding the absence of bubbles. Platinum electrodes were put in contact and connected to the power supply in order to generate an electric field with the colloid.

The value of electrophoretic mobility is given directly by the equipment and the zeta potential is determined according to the following equation.

Smoluchowski equation (18):

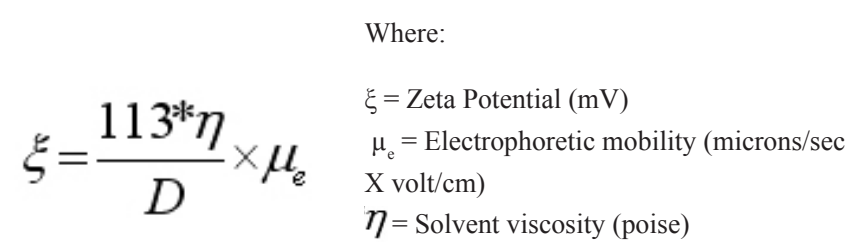

\section{Elemental Analysis}

$\mathrm{C}$ and $\mathrm{H}$ content were determined by a Fisons Instrument EA 1108 automatic analyzer, using sulfanilamide as standard. Dy was determined by atomic absorption in a Perkin-Elmer 3100 with Dy lamp.

\section{FT-IR studies}

Infrared spectra were measured through a FT-IR Nicolet Magna 5 PC spectrophotometer coupled to a PC loaded with Omnic software analysis. Films were placed into the holder directly, in the IR laser beam. Spectra were recorded at a resolution of $4 \mathrm{~cm}^{-1}$ and 128 scans were accumulated between 400 and $4000 \mathrm{~cm}^{-1}$.

\section{Thermogravimetric studies}

A Perkin Elmer model TGA-7 thermogravimetric analysis (TGA) system with a microprocessor driven temperature control unit and a TA data station was used. The mass of the sample was generally in the range $2-3 \mathrm{mg}$. The sample was placed in the balance systems equipment and the temperature was raised from 25 until $550^{\circ} \mathrm{C}$ at a heating rate of a $10^{\circ} \mathrm{C} / \mathrm{min}$. The mass sample pan was continuously recorded as a function of the temperature.

\section{Conductivity}

The electrical conductivity measurements were carried out using $120 \mathrm{mg}$ samples and pressed up to $16600 \mathrm{psi}$ making a disc in which the electrical resistivity was measured, using a RCL Bridge Fluke PM 6304. The electric resistivity $\mathrm{R}$ is related to the geometry of the section, in which a current flows with proportionality $\rho$ constant, called electrical resistivity, a characteristic parameter of each material. The equation that represents this relation is:

$$
R=\rho \frac{L}{A} ; \rho=(\Omega m) \quad \begin{aligned}
& \mathrm{L}=\quad \text { Thickness of the sample. } \\
& \mathrm{A}=\quad \text { Transversal area where the current } \\
& \text { flow run. }
\end{aligned}
$$

\section{Kinetic stability}

The stability for each one of the colloidal dispersions was studied in time, through their both physical and chemical behavior. The flocculation time of the sols as a function of time was followed the first $24 \mathrm{~h}$ and then every day by visual and zeta meter measurements.

\section{Medium FTIR}

Infrared Spectra were obtained using a Nicolet Magna 5PC Spectrometer. $\mathrm{KBr}$ pellets were made for all films. Spectra were recorded at a resolution of 2 $\mathrm{cm}^{-1}$ and a minimum of 128 scans were accumulated. Omnic 5.2a program was used for data analysis.

\section{Luminescence}

Luminescence measurements were carried out for both colloids and particles in solid state, and an ISS PC1 fluormeter was used for this purpose. In order to achieve the luminescence measurements of the colloids, a quartz cell of four transparent faces, sealed with septa was used. This process was carried out in a dry box to avoid the humidity and oxygen interaction with the sample. The reference used, corresponds to pure solvent.

\section{RESULTS AND DISCUSSION}

Colloidal particles are nanostructures and because of the solvation, they are in constant Brownian movement. They can get combined and agglomerated producing thus, small clusters. They are thermodynamically unstable and furthermore, their equilibrium conditions can be modified in order to induce the flocculation or coagulation of dispersed particles.

Another important factor in the particle stabilization is the solvation process, and due to this phenomenon, nanoparticles are completely surrounded by solvated molecules avoiding thus the clustering. Solvation depends on the solvent affinity by the atoms forming the surface of the particles. The affinity is the result of a mutual saturation tendency of the non-balanced valence field around the atoms. On the other hand, not only steady stabilization is responsible for the colloidal particle stabilization. Among them, some donor inductive effect and/or electron release are capable to stabilize the clusters in the colloids. The presence of small fragments of solvents is due to the metal evaporation by resistive heating and the collision at high kinetic energy produces vapor fragmentation of the incoming solvents, although it represents a very small amount that does not affect the main properties of the colloidal system.

The following scheme shows the synthesis of dysprosium colloids in

\begin{tabular}{|c|c|c|}
\hline & & \multirow[b]{2}{*}{$\begin{array}{c}\mathrm{Dy}\left(\mathrm{CH}_{3} \mathrm{OCH}_{2} \mathrm{CH}_{2} \mathrm{OH}\right) \\
\text { Colloidal Matrix } \\
\text { Col orless }\end{array}$} \\
\hline \multirow[t]{2}{*}{$\begin{array}{c}\text { Dy } \\
\text { (Atoms, Vapor) }\end{array}$} & \multirow[t]{2}{*}{$\begin{array}{c}\mathrm{CH}_{3} \mathrm{OCH}_{2} \mathrm{CH}_{2} \mathrm{OH} \\
\text { (Vapor) }\end{array}$} & \\
\hline & & $\begin{array}{l}\text { Warm U } \\
\text { (1 Hour) }\end{array}$ \\
\hline $\mathrm{Dy}\left(\mathrm{CH}_{3} \mathrm{OCH}_{2} \mathrm{CH}_{2} \mathrm{OH}\right)$ & Pure nitrogen Flow & $\downarrow$ \\
\hline $\begin{array}{l}\text { Colloid with organic } \\
\text { solvent fragments } \\
\text { in the }\end{array}$ & (0.5 Hour) & $\begin{array}{c}\mathrm{Dy}\left(\mathrm{CH}_{3} \mathrm{OCH}_{2} \mathrm{CH}_{2} \mathrm{OH}\right) \\
\text { Colorless Colloid }\end{array}$ \\
\hline
\end{tabular}
2-methoxyethanol by the CLD method.

Scheme 1 Colloids and active solids from dysprosium in 2-methoxyethanol

The stability of the colloids was observed at room temperature, in order to determine the kinetic stability. The cocondensation method generates some organic fragments by the resistive heating of the crucible by solvent pyrolisis. Table 1 summarizes the stability of the colloidal systems under study. 
Table 1. Dy colloid stability with different solvents

\begin{tabular}{|c|c|c|}
\hline Solvent & $\begin{array}{l}\text { Concentration } \\
\text { (M) }\end{array}$ & $\begin{array}{c}\text { Stability/Color Matrix/Color } \\
\text { Colloid }\end{array}$ \\
\hline 2-methoxyethanol & $\begin{array}{l}2.5 \mathrm{E}-4 \\
5.0 \mathrm{E}-4 \\
1.0 \mathrm{E}-3 \\
2.0 \mathrm{E}-3\end{array}$ & $\begin{array}{c}>6 \text { months/Colorless Matrix/ } \\
\text { Colorless Colloid } \\
>6 \text { months/Colorless Matrix/ } \\
\text { Colorless Colloid } \\
>6 \text { months/Colorless Matrix/ } \\
\text { Colorless Colloid } \\
>6 \text { months/Colorless Matrix/ } \\
\text { Colorless Colloid }\end{array}$ \\
\hline 2-propanol & $\begin{array}{l}2.5 \mathrm{E}-4 \\
5.0 \mathrm{E}-4 \\
1.0 \mathrm{E}-3 \\
2.0 \mathrm{E}-3\end{array}$ & $\begin{array}{c}>3 \text { months/Colorless Matrix/ } \\
\text { Colorless Colloid } \\
>3 \text { months/Colorless Matrix/ } \\
\text { Colorless Colloid } \\
>3 \text { months/Colorless Matrix/ } \\
\text { Colorless Colloid } \\
>3 \text { months/Colorless Matrix/ } \\
\text { Colorless Colloid }\end{array}$ \\
\hline $\begin{array}{c}1,2- \\
\text { dimethoxyethane }\end{array}$ & $\begin{array}{l}2.5 \mathrm{E}-4 \\
5.0 \mathrm{E}-4 \\
1.0 \mathrm{E}-3 \\
2.0 \mathrm{E}-3\end{array}$ & $\begin{array}{c}1 \text { day/Colorless Matrix/Colorless } \\
\text { Colloid } \\
\text { 7hours/Colorless Matrix/Colorless } \\
\text { Colloid } \\
5 \text { hours/Blue Matrix/Colorless } \\
\text { Colloid } \\
1 \text { hour/Blue Matrix/Colorless } \\
\text { Matrix }\end{array}$ \\
\hline
\end{tabular}

From table 1 it can observed that some colloidal matrix are brown or blue and this phenomena is due to some optical properties of small clusters $(2-6$ atoms) which, in some cases, have the same color than the colloid. The matrix color changes when the small clusters are aggregating more atoms. More atoms and the particle size are growing and their optical properties are changing due to the different wavelength absorption ${ }^{19-21}$.

The Dy colloids in 2-methoxyethanol are the most stable, followed by the Dy colloids prepared in 2-propanol and acetone. The lower stability was observed for the Dy in 1, 2-dimethoxyethanol colloids.

The more stable colloids are related with the presence of alcoxy and carbonyl groups, which play an important role in the polarity of the functional group as they are able to produce some kind of bond with the surface of the metal clusters.

On the other hand, metal concentration in the colloids is also related to their stabilities. For colloids, when metal concentration decreases, their metal stability increases. This is due to the lower energy needed to stabilize the metal particles in order to produce a thermodynamically stable system.

\section{Electrophoretic Mobility}

Once the colloids are synthesized, their electro kinetic mobilities were obtained. The Zeta-Meter cell was charged in a dry box in order to avoid the metal particle oxidation, keeping the original electro kinetic properties of the colloids. The following table 2 summarizes the values obtained for $\zeta$ (in $\mathrm{mV}$ ) for colloidal Dy in the organic solvent.
Table 2. Zeta potential values $\zeta$ (in $\mathrm{mV}$ ) of Dy colloids.

\begin{tabular}{|c|c|c|c|}
\hline Solvent & Concentration (M) & $\zeta(\mathrm{mV})$ & Charge \\
\hline 2-methoxyethanol & $\begin{array}{l}2.5 \mathrm{E}-4 \\
5.0 \mathrm{E}-4 \\
1.0 \mathrm{E}-3 \\
2.0 \mathrm{E}-3\end{array}$ & $\begin{array}{l}0.497 \\
0.489 \\
0.456 \\
0.301\end{array}$ & Negative \\
\hline 2-propanol & $\begin{array}{l}2.5 \mathrm{E}-4 \\
5.0 \mathrm{E}-4 \\
1.0 \mathrm{E}-3 \\
2.0 \mathrm{E}-3\end{array}$ & $\begin{array}{l}1.113 \\
0.999 \\
0.902 \\
0.886\end{array}$ & Negative \\
\hline $\begin{array}{c}1,2- \\
\text { dimethoxyethane }\end{array}$ & $\begin{array}{l}2.5 \mathrm{E}-4 \\
5.0 \mathrm{E}-4 \\
1.0 \mathrm{E}-3 \\
2.0 \mathrm{E}-3\end{array}$ & $\begin{array}{l}0.440 \\
0.294 \\
0.254 \\
0.193\end{array}$ & Negative \\
\hline
\end{tabular}

From the results it can be concluded that another stabilizer effect for the colloids is observed. Besides of solvation effect (steric stabilization) it must be considered the electric stabilization, which is corroborated by these measurements. The presence of the double layer where the potential on the surface of the static layer is the zeta potential can be observed. This stabilization effect can be explained because of the electric double layers repulsion, keeping the particles well dispersed in the organic media. As a consequence of the higher $\zeta$ values for this Dy colloids in 2-methoxyethanol is the ranging from 0.88 to $1.11 \mathrm{mV}$, while the 2-propanol and 2-propanone are lower. Dy colloids in 1,2-dimethoxyethanol are the most unstable, which is in agreement with their smaller $\zeta$ values.

According to data reported by Cardenas ${ }^{17,21}$ the negative charge of the particles are due to the adsorption of organic and ionic fragments produced during the reaction and the gas atoms generated by the heating resistant and lower pressures, acquire a great kinetic energy, crashing solvent molecules and producing small fragments.

\section{UV-Visible Spectroscopy}

Since we are dealing with colloidal system of lanthanides metals in the UV-Vis we only should expect bands in the UV range.

The following studies by UV spectroscopy are summarized in the following table.

Table 3. Dy colloids absorption bands.

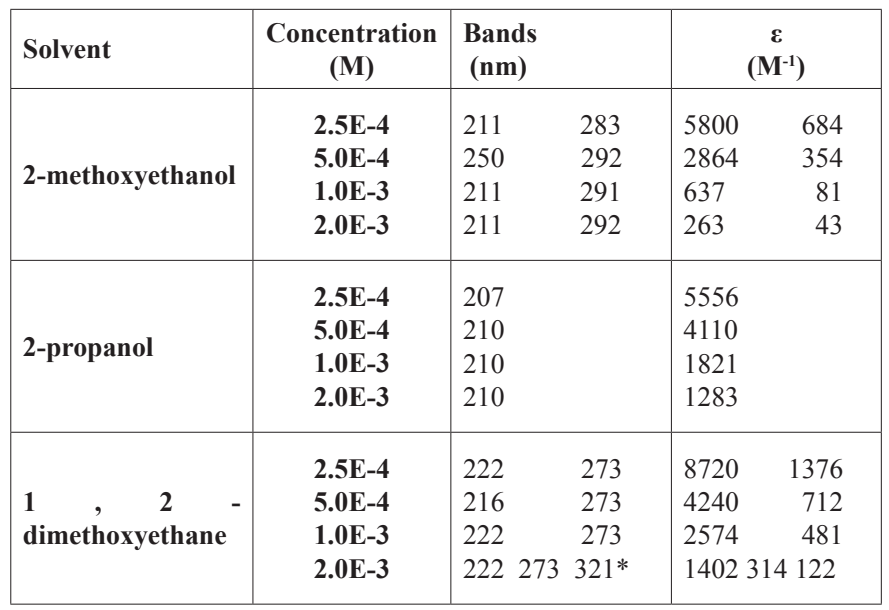

*After 48 hours.

UV spectroscopy is used to determine the different types of interaction between the dysprosium and the solvent. The interpretation of the UV spectra of metal lanthanides is quite difficult due to the requirements of the molecular orbital treatment. The assignment of the different kinds of transition related 
to an absorption band in this range is dealing with their molar extinction coefficient.
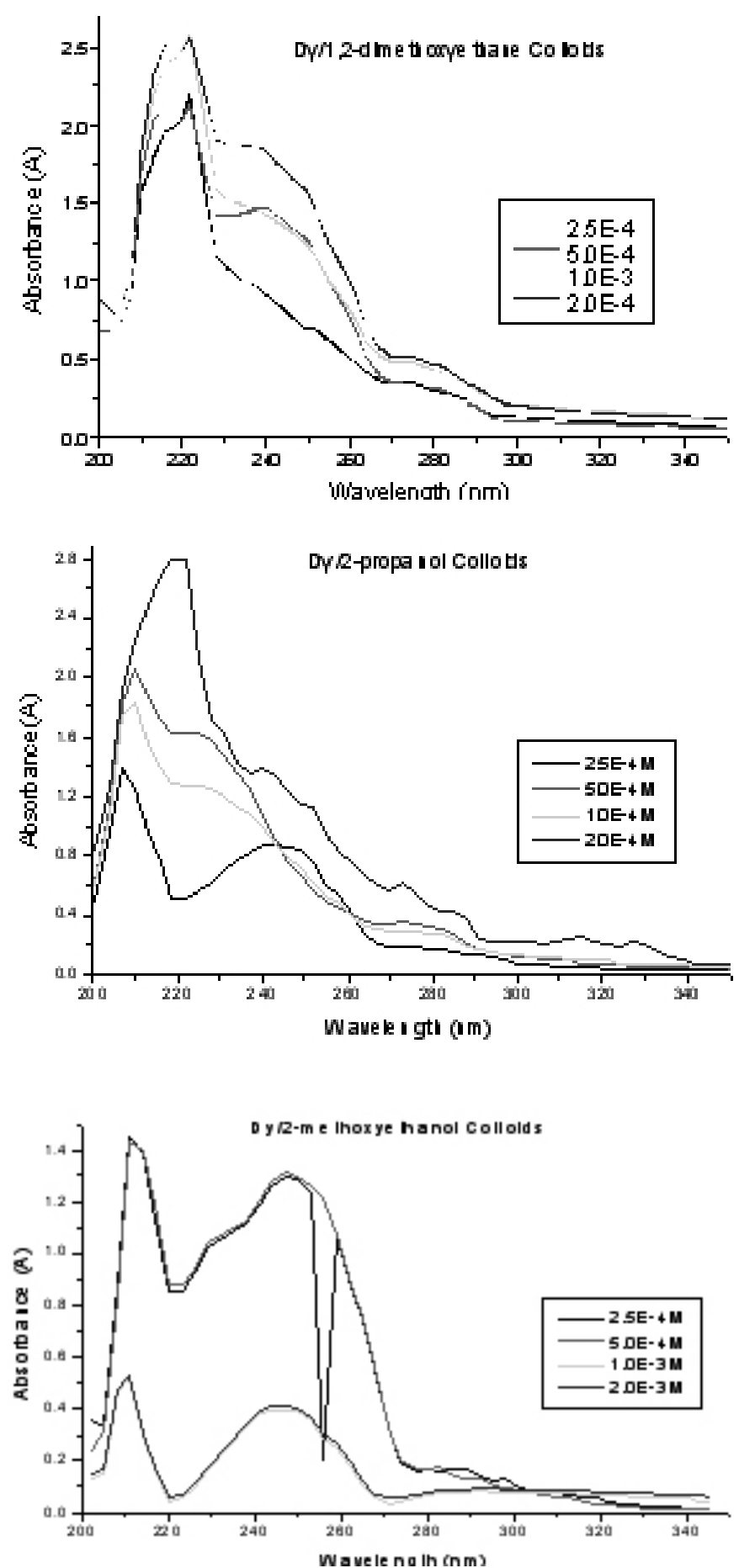

Figure 1. UV Dy colloids absorption spectra.

In the three cases we can observe 2 main bands. Assigned transfer charge and typical transition of the solvent depends on the molar extinction coefficient $(\varepsilon)$. Some bands are related to charge transfers, as they exhibit the shoulder that appears when some forbidden transitions are produced, but since we are dealing with lanthanide metals, that possess $f$ and $d$ half loaded orbitals, they do not follow the normal selection rules 19,20 .

The three solvents in the study behave quite differently. In the Dy 2-methoxyethanol with lower concentration (2.5E-4 M) only one band appears, corresponding to the solvent electronic transition $\left(\pi \rightarrow \pi^{*}\right)$. Colloids with double metal concentrations exhibit a more metallic behavior. The colloid with greater metal concentration (2.0E-3 M), exhibits a complete metal behavior and the two bands correspond to the inter band transition corresponding to the electronic transitions in the metal particles.

Dy colloids in 2-propanol in four concentrations shows absorption bands corresponding to the electronic transition of the solvent $\left(\pi \rightarrow \pi^{*}\right)$. $\varepsilon$ values decrease, which is probably related to the interaction between solvent molecules and metal particles.

The two colloids of Dy in 1,2-dimethoxyethane at lower concentrations (2.5E-4 and 5.0E-4 M) show only electronic transitions, typical of the solvent and from the $1.0 \mathrm{E}-3 \mathrm{M}$ concentration the band that appears to have a shift at $273 \mathrm{~nm}$ and behaves completely metallic. For the colloid with a higher metal concentration $(2.0 \mathrm{E}-3 \mathrm{M})$, the value of $\varepsilon$ decreases considerable and besides show other two band attributed to inter band transitions which indicates a more metallic behavior. One of these bands appears at $321 \mathrm{~nm}$ after $48 \mathrm{~h}$ since the first spectra was taken.

\section{Transmission Electron Microscopy (TEM)}

The sizes were obtained by electron micrograph and by measurements of the particle diameters assuming a spherical shape for a certain population randomly taken. A frequency histogram was built in order to obtain the size distribution. The standard deviation was obtained for each measurement. Particle sizes for the Dy colloid in 2-methoxyethanol, 2-propanol and 1,2dimetoxyethane are summarized in Table 4.

Table 4. Particle size distribution for Dy colloids

\begin{tabular}{|c|c|c|}
\hline Solvent & $\begin{array}{c}\text { Concentration } \\
\text { (M) }\end{array}$ & $\begin{array}{c}\text { Particle Size } \\
( \pm 0.4 \mathbf{~ n m})\end{array}$ \\
\hline 2-methoxyethanol & $\begin{array}{l}2.5 \mathrm{E}-4 \\
5.0 \mathrm{E}-4 \\
1.0 \mathrm{E}-3 \\
2.0 \mathrm{E}-3\end{array}$ & $\begin{array}{l}11.6 \\
9.9 \\
7.9 \\
2.5\end{array}$ \\
\hline 2-propanol & $\begin{array}{l}2.5 \mathrm{E}-4 \\
5.0 \mathrm{E}-4 \\
1.0 \mathrm{E}-3 \\
2.0 \mathrm{E}-3\end{array}$ & $\begin{array}{l}4.3 \\
2.5 \\
3.3 \\
2.5\end{array}$ \\
\hline 1,2-dimethoxyethane & $\begin{array}{l}2.5 \mathrm{E}-4 \\
5.0 \mathrm{E}-4 \\
1.0 \mathrm{E}-3 \\
2.0 \mathrm{E}-3\end{array}$ & $\begin{array}{c}3.7 \\
\text { not determined } \\
\text { not determined } \\
\text { not determined }\end{array}$ \\
\hline
\end{tabular}

The particle size ranges from 2.5 to $11.6 \pm 0.4 \mathrm{~nm}$, which is in the range of other previously reported nanoparticles ${ }^{21-23}$.

In some cases, it can be observed a relation between particle size and kinetic stability for the same solvent. At lower concentrations, the particle size is smaller and besides, with higher stability ${ }^{19-21}$. Figure 2 shows the micrographs obtained by TEM of the colloids as well as their corresponding histograms. 


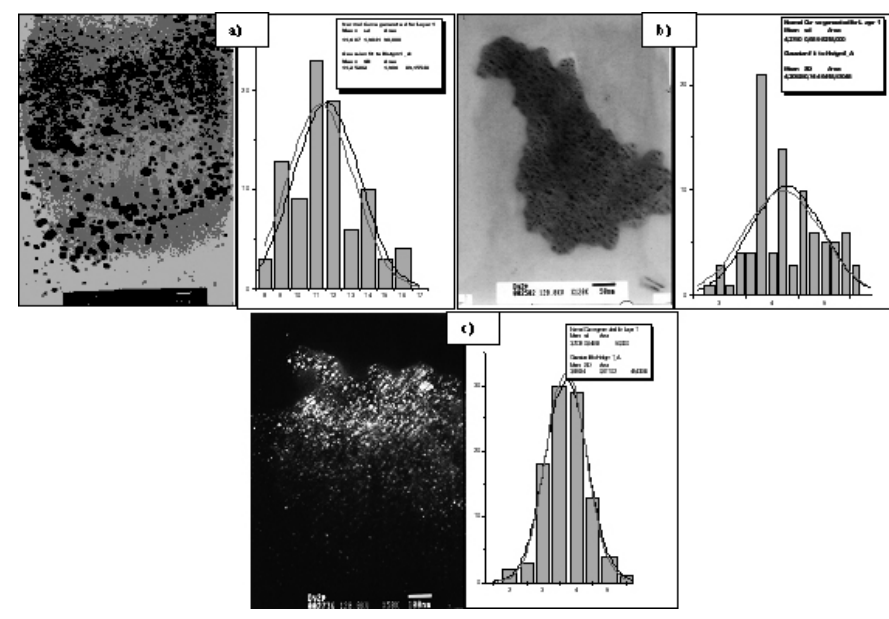

Figure 2a. TEM (light field) and histogram of Dy/2-methoxyethanol(2.5E-4 $\mathrm{M})$; Figure 2b. TEM (light field) and histogram of Dy/2-propanol (2.5E-4 M); Figure 2c. TEM (dark field) and histogram of Dy/1,2-dimetoxyethane (2.5E-4 M)

The micrographs were taken in light field and just a few of them in dark field resolution and, at that magnification, most of the particles are spherical randomly, distributed and similar to those reported for $\mathrm{Au}$ and $\mathrm{Bi}$, among others ${ }^{24,25}$.

In order to obtain a greater thermodynamic stability they agglomerate, generating small clusters (see Figure 3).

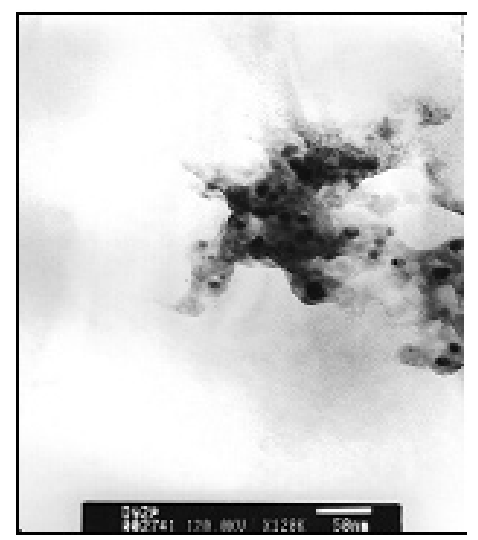

Figure 3. TEM light field Dy/2-methoxyethanol

\section{Electron diffraction}

From the images analysis (see fig.4) the 2-methoxyethanol shows higher crystalline particles. The presence of crystalline particles decreases for 2-propanol and 1,2-methoxyethanol.
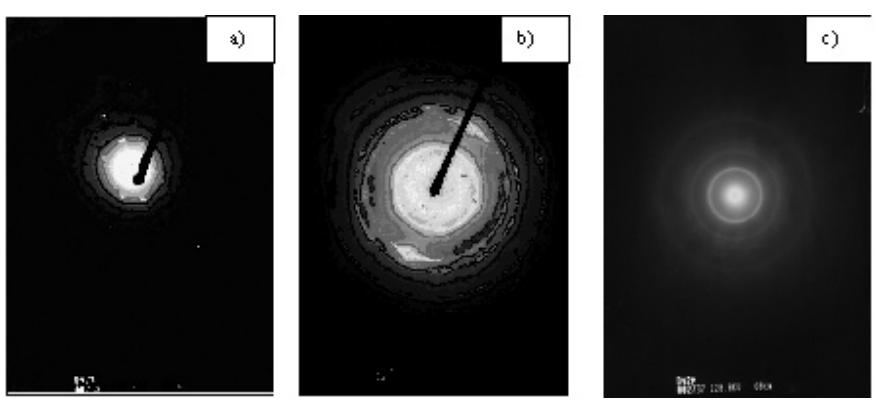

Figure 4. Electron diffraction micrograph for the Dy colloids a) 2-methoxyethanol, b) 2-propanol and c) 1,2-dimethoxyethane.
Table X summarizes the analysis of the diffractions and their identification. Most of the particles are amorphous and some small crystallites are shown.

Table X. Electron diffraction assignment.

\begin{tabular}{|l|c|c|c|c|c|c|}
\hline \multicolumn{1}{|c|}{ Colloid } & $\begin{array}{c}\mathbf{N}^{\circ} \\
\text { Ring* }\end{array}$ & $\begin{array}{c}\text { Diameter } \\
(\mathbf{c m})\end{array}$ & $\begin{array}{c}\mathbf{d} \\
(\mathbf{\AA}) \\
\text { exp }\end{array}$ & $\begin{array}{c}\mathbf{d} \\
\mathbf{(} \mathbf{\AA}) \\
\text { tablas }\end{array}$ & (hkl) & Phase \\
\hline $\begin{array}{l}\text { Dy/2- } \\
\text { methoxyethanol }\end{array}$ & 1 & 1.15 & 3.66 & 3.31 & $(100)$ & $\mathrm{Dy}_{2} \mathrm{O}_{3}$ \\
\hline & 2 & 1.50 & 2.81 & 2.81 & $(002)$ & $\mathrm{Dy}$ \\
\hline Dy/2-propanol & 1 & 1.28 & 3.29 & 3.31 & $(100)$ & $\mathrm{Dy}_{2} \mathrm{O}_{3}$ \\
\hline & 2 & 1.48 & 2.84 & 2.81 & $(002)$ & $\mathrm{Dy}$ \\
\hline $\begin{array}{l}\text { Dy/1,2- } \\
\text { dimethoxyethane }\end{array}$ & 1 & 1.26 & 3.34 & 3.31 & $(100)$ & $\mathrm{Dy} \mathrm{O}_{3}$ \\
\hline & 2 & 1.47 & 2.86 & 2.81 & $(002)$ & $\mathrm{Dy}$ \\
\hline
\end{tabular}

The most intense rings or points were measured ${ }^{26}$.

The three cases exhibit crystallographic phases, mainly of $\mathrm{Dy}_{2} \mathrm{O}_{3}(100)$ and Dy (002). The Dy oxidation probably occurs in the surface of the colloidal particles, because of the higher reactivity of the nanoparticles ${ }^{22}$.

\section{Energy Dispersive X-ray (EDX).}

The EDX helps to confirm the presence of the Dy in the nanoparticles. The dysprosium exhibits three signals at 7.4, 7.5 and 7.6 KeV $(\mathrm{L} \alpha)$. The other signals corresponding to $\mathrm{Cu}$, belong to the grids, at $8.1 \mathrm{KeV}(\mathrm{K} \alpha)$ (see Figure $5)$.

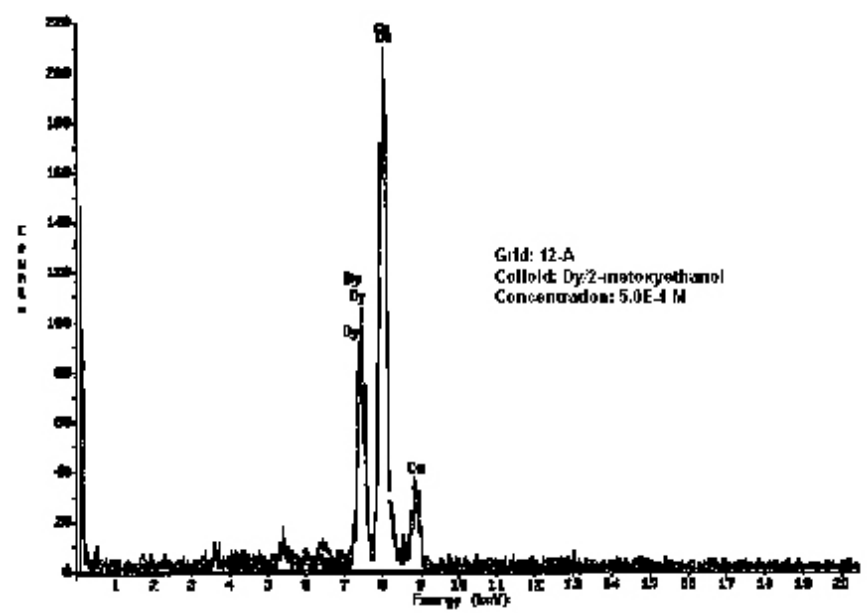

Figure 5. EDX spectra of Dy/2-methoxyethanol colloid (5.0E-4M).

\section{Luminescence}

According to some data reported, the luminescence for Dy $(5-\mathrm{Brnic})_{3}\left(\mathrm{H}_{2} \mathrm{O}\right)_{3}$ (5-Brnic) complex = bromo nicotinic acid) exhibits two emission bands with excitation at $271 \mathrm{~nm}$ : one at $480 \mathrm{~nm}$ and other appears at $570 \mathrm{~nm}$, corresponding to the characteristic emission of the corresponding transition ${ }^{4} \mathrm{~F}_{9 / 2} \rightarrow{ }^{6} \mathrm{H}_{\mathrm{J}}(\mathrm{J}=$ $15 / 2 ; 13 / 2)$ of $\mathrm{Dy}^{3+}$ ion.

For the colloidal system under study, only the luminescence spectra corresponding to Dy-2-methoxyethanol were measured.

Under successive excitations, the $\lambda$ ranges up to $8 \mathrm{~nm}$, running emission spectra from 260 to $500 \mathrm{~nm}$. It could be observed for the colloids with lower amount of metal $(2.5 \mathrm{E}-4,5.0 \mathrm{E}-4$ and $1.0 \mathrm{E}-3)$ that only one emission band around $275 \mathrm{~nm}$ appears. On the other hand, for colloids of greater 
Table XI. Emission bands of Dy-2-methoxy ethanol.

\begin{tabular}{|c|c|c|c|}
\hline \multirow{2}{*}{ Colloid } & $\begin{array}{c}\text { Concentration } \\
(\mathbf{M})\end{array}$ & $\begin{array}{c}\lambda \\
\text { Emission } \\
(\mathbf{n m})\end{array}$ & $\begin{array}{c}\text { Quantum yield } \\
\text { (Arbitrary units) }\end{array}$ \\
\hline \multirow{3}{*}{$\begin{array}{c}\text { Dy/2-methoxy } \\
\text { ethanol }\end{array}$} & $2.50 \mathrm{E}-4$ & 280 & 23869 \\
\cline { 2 - 4 } & $5.0 \mathrm{E}-4$ & 280 & 57950 \\
\cline { 2 - 4 } & $1.0 \mathrm{E}-3$ & 280 & 54527 \\
\cline { 2 - 4 } & $2.0 \mathrm{E}-3$ & 280 & 62344 \\
& & 356 & 149493 \\
\hline
\end{tabular}

metal concentration, the presence of two emission bands can be observed, one of them appears at $275 \mathrm{~nm}$ (present in all of them) and a second emission band that appears at $375 \mathrm{~nm}$. See table XI.

The difference in the shift of the emission band is produced by a pronounced metallic character of the colloid. Some applications in this field have been already reported ${ }^{27}$.

According to S. Yi-Shan and coworkers studies ${ }^{28}$, the intensity of luminescence for complexes under a same maximum excitation is a key factor to understand the charge transfer mechanism between the ligand and the metal ion. Greater values in the emission intensity, implies a higher energy transfer value involved in the process.

\section{CONCLUSIONS}

It is possible to obtain Dy colloids in organic solvents with different stability at room temperature depending upon both solvent and concentration. The most stable colloids results to be Dy-2-methoxyethanol, then followed by the Dy-2-propanol and the less stables are Dy-2-methoxyethane, being for just a few hours. The zeta potential $(\xi)$ is low in comparison to colloids in aqueous media, which corroborates the low stability of the metallic colloids in aqueous media. The polarity of this colloids are due to the inclusion of the solvent fragments in the metal clusters produced in the reaction, which helps to stabilize the metal particles.

By means of UV-VIS spectroscopy, it was possible to probe the inclusion of the organic fragment coming from the solvent fragmentation. For the 2-methoxyethanol colloids, it can be observed that colloid particles possess a metallic behavior (inter band transition) and electronic transition in the solvent $\left(\pi \rightarrow \pi^{*}\right)$ which decreases the $\varepsilon$ value, due probably to the solvent-metal clusters interaction. The colloids in 1,2-dimetoxyethane of lower concentration, exhibit only inter bands transition. However, for higher concentrations there is a mixture of metallic and solvent bands.

Colloids that exhibit a higher particle sizes are also the most stables ( Dy2-methoxyethanol), the colloids of Dy-2-propanol possesses an intermediate size that can be correlated with their stability. On the other hand, the Dy-2methoxy ethane, due to its lower stability, can flocculate faster, increasing the clustering of colloidal particles.

In the case of electron diffraction of the colloids, two crystallographic phases have been found, which is attributed to the $\mathrm{Dy}_{2} \mathrm{O}_{3}(100)$ and Dy (002) planes. The presence of the phase $\mathrm{Dy}_{2} \mathrm{O}_{3}(100)$ is due to the surface oxidation of the particles.

The presence of the metal in the colloids after solvent evaporation is corroborated by EDX analysis with signals at 7.4, 7.5 and 7.6 KeV and they can be assigned to the $\mathrm{L} \alpha$ level of the metal orbitals.

Luminescence was observed in the UV region for 2-methoxy ethanol colloids.

\section{ACKNOWLEDGMENTS}

The authors would like to thank the financial support of Fondecyt Grant \# 1040456 and Electron Microscopy facilities from Universidad de Concepción.

\section{REFERENCES}

1. The Chemistry of the Lanthanides, Moeller, Reinold Publishing Corporation, New York, 1963, 12-34.

2. C.J. Schlesener, A.B. Ellis, Organometallics, 2, 529 (1983).

3. H. G. Brittain, J.H. Meadows, W.J. Evans, Organometallics, 2, 1661 (1983).

4. G. K. Liu, J. V. Beitz, J. Alloys Comp. 157, 180 (1992).

5. R. P. Pao, Solid State Commun. 99, 439, (1996)

6. L. Lewis, Chem. Rev. 93, 2693, (1993)

7. S. Yi-Shan, Y. Bing, C. Zhen-Xia, J. Solid State Chem. 177, 3805, (2004).

8. M. D. Musik, D.C. Keating, M.H. Keefe and M.J. Natan, Chem. Mater. 9, 1499, (1997).

9. Mc Henry and Laughlin, Acta Mater., 48, 223, (2000).

10. E. M. Raminovich, J. Scmulovich, V. J. Fratello, N. Y. Kopyov, Am. Ceram. Soc. Bull. 6, 1505, (1987).

11. T. Mirkovic, M.A. Hines, P.N. Sreekumari, G.D. Scholes, Chem. Mater. 17, 3451, (2005).

12. Compendio de Química Coloidal, Jirguensons, Straumanis, Compañía Editorial Continental, México, ${ }^{\text {st }}$ Edition, 1965, 25-27.

13. W. Ostwald, Colloid-Zeitschrift 1, 331, (1907).

14. M. T. Franklin, K.J. Klabunde and E. B. Dale, Langmuir 2, 259 (1986).

15. G. Mie, Ann. Phys. 11, 1067, (1908).

16. G. Cárdenas T., Y. León, Y. Moreno, O .Peña, Colloid Polym. Sci. 284 644, (2006).

17. G. Cárdenas T, J. Chil. Chem. Soc. 50, 603 (2005).

18. M. Smoluchowski, Handbuch der Electrizitát und des Magnetismus, Vol.2 Leipzig, Germany, 366, 1914.

19. Spectroscopy and Structure of Metal Chelate Compounds, John Wiley \& Sons Inc, USA, Nakamoto, Mc Carthy, 1968, 73-80.

20. Creighton and Eadon, J. Chem. Soc. Faraday Trans., 87, 3881 (1991)

21. G. Cárdenas, R. Oliva, Colloid Polym. Sci., 281, 27, 2003. (Paper Pd-Ag)

22. (a)G. Cárdenas , Ricardo Oliva, Mat. Res. Bull. 35, 2227, (2000), (b) G. Cárdenas, R. Oliva, Bol. Soc. Chil. Quím., 38, 301, (1993).

23. G. Cárdenas, J.G. Contreras and O. Godoy, J. Chil. Chem. Soc., 51, 3, (2006).

24. G. Cárdenas T., C. Muñoz D. and V. Vera L., Bol. Soc. Chil. Quím. 41, 235, (1996)

25. G. Cárdenas T., V. Vera L., H. Soto Z., Colloids and Polymer Sci. 274, 145-152 (1996)

26. Powder Diffraction File, American Society for Testing Materials, Department of Geology, University of Chicago, 1983, Vol. 15, 430. Ibid. Vol. 19, 436.

27. J. Plieth, J. Phys. Chem., 86, 3166, (1982).

28. S. Yi-Shan, Y. Bing, C. Zhen-Xia, J. Solid State Chem. 177, 3805, 2004. 